\title{
Negative-ion implanter for powders and its application to nanometer- sized metal particle formation in the surface of glass beads
}

\section{$\operatorname{AUTHOR}(\mathrm{S})$ :}

Tsuji, Hiroshi; Kido, Shunsuke; Sasaki, Hitoshi; Gotoh, Yasuhito; Ishikawa, Junzo

\section{CITATION:}

Tsuji, Hiroshi ...[et al]. Negative-ion implanter for powders and its application to nanometer-sized metal particle formation in the surface of glass beads. REVIEW OF SCIENTIFIC INSTRUMENTS 2000, 71(2): 804-806

\section{ISSUE DATE:}

2000-02

URL:

http://hdl.handle.net/2433/39800

\section{RIGHT:}

Copyright 2000 American Institute of Physics. This article may be downloaded for personal use only. Any other use requires prior permission of the author and the American Institute of Physics. 


\title{
Negative-ion implanter for powders and its application to nanometer-sized metal particle formation in the surface of glass beads
}

\author{
Hiroshi Tsuji, ${ }^{\text {a) }}$ Shunsuke Kido, Hitoshi Sasaki, Yasuhito Gotoh, and Junzo Ishikawa \\ Department of Electronic Science and Engineering, Kyoto University, Yoshida-honmachi, Sakyo-ku, \\ Kyoto 606-8501, Japan
}

(Presented on 6 September 1999)

\begin{abstract}
We have developed a negative-ion implanter for uniform implantation into each powder surface without particle scattering. It consists of a plasma sputter-type negative-ion source, a mass separator, an acceleration tube, a lens, $X-Y$ deflectors, a $90^{\circ}$ deflector, and a Faraday cup with an agitator. The electrostatic $90^{\circ}$ deflector bends a horizontal beam to a vertical direction and leads it into the Faraday cup. The agitator is an electromagnetic vibrator at a frequency of $120 \mathrm{~Hz}$, which mixes particles for whole surface treatment and uniform implantation. In this implanter, we obtained no scattering implantation for spherical oxide beads with diameters ranging from 5 to $1000 \mu \mathrm{m}$ in an agitated state, and also obtained a good uniformity of implanted atoms among beads. For an application of the negative ion implantation into powders, copper ions were implanted into soda-lime glass beads and plates at conditions of 50 and $30 \mathrm{keV}$, respectively, with 1 $\times 10^{17}$ ions $/ \mathrm{cm}^{2}$. In linear optical properties, both implanted samples show a clear absorption at a photon energy of $2.2 \mathrm{eV}$ due to resonance absorption of copper surface plasmon. In addition, the implanted glass plate shows the large third-order nonlinear susceptibility, $\chi^{(3)}=1.3 \times 10^{-7}$ esu. These results suggest the existence of copper nanometer-sized particles in glass. (C) 2000 American Institute of Physics. [S0034-6748(00)67502-0]
\end{abstract}

\section{INTRODUCTION}

The use of negative ions as implant particles in ion implantation provides an advantage of almost "charge-up free" phenomena for substrates of insulator and isolated electrodes. ${ }^{1-4}$ Therefore, the negative-ion implantation is expected to be a useful method for surface modification of powders. Powders have been used in many fields such as catalysis industry and medical treatments. Surface treatment of powder particles by ion implantation is desired to have more effective and newly functional properties.$^{5-9}$ However, materials of the powder in most cases are insulators such as oxides. In the conventional ion implantation with positive ions, a charging problem is inevitable that causes particle scattering and miss-control of implantation. In addition, agitation of powders is required for implantation into the whole surface of each particle. This agitation makes the scattering at a charging voltage lower than that for stationary state due to decrease in the van der Waals force between particles. ${ }^{10}$

To solve this scattering problem, we developed negativeion implanter for powders with an agitator. The nonscattering implantation by using negative ions was already reported. ${ }^{11-13}$ In this article, we describe the negative-ion implanter for powders and its features, and also show an application of negative-ion implantation to forming copper nanometer-sized particle in powder surface.

\section{NEGATIVE-ION IMPLANTATION FOR POWDER SURFACE}

\section{A. Negative-ion implanter for powder}

Figure 1 shows a schematic configuration of a developed negative-ion implanter. The implanter consists of a rfplasma-sputter-type negative-ion source, ${ }^{14,15}$ a massseparator, an acceleration column, a $Q$ lens and two set of deflectors for $X-Y$, a chamber for silicon substrate (chamber 1), an electrostatic $90^{\circ}$ deflector, and a chamber for powder (chamber 2). The source is a rf-plasma-sputter-type heavy negative ion source with a sputtering target of an outer diameter of $34 \mathrm{~mm}$ with a spherically concave surface, which can deliver an ion current in $\mathrm{mA}$-class. This implanter can accelerate ions up to $125 \mathrm{keV}$ by the acceleration column. The $X-Y$ deflectors are for elimination of neutral beam and for scanning ion beam. Figure 2 shows an enlarged configuration around Chamber 2. The electrostatic $90^{\circ}$ deflector bends a horizontal beam to a vertical direction and leads it into the Faraday cup. In the center of the bottom plate of Faraday cup, an agitator of electromagnetic vibrator was placed. It can mix powder particles for implantation into whole surface of each particle and uniform implantation by vibrating the holder at a frequency of $120 \mathrm{~Hz}$ with an amplitude of $0.5 \mathrm{~mm}$. Detail features of the negative-ion implantation by using this implanter were already reported. ${ }^{13}$ Therefore, we described here only a brief summary of them.

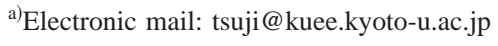




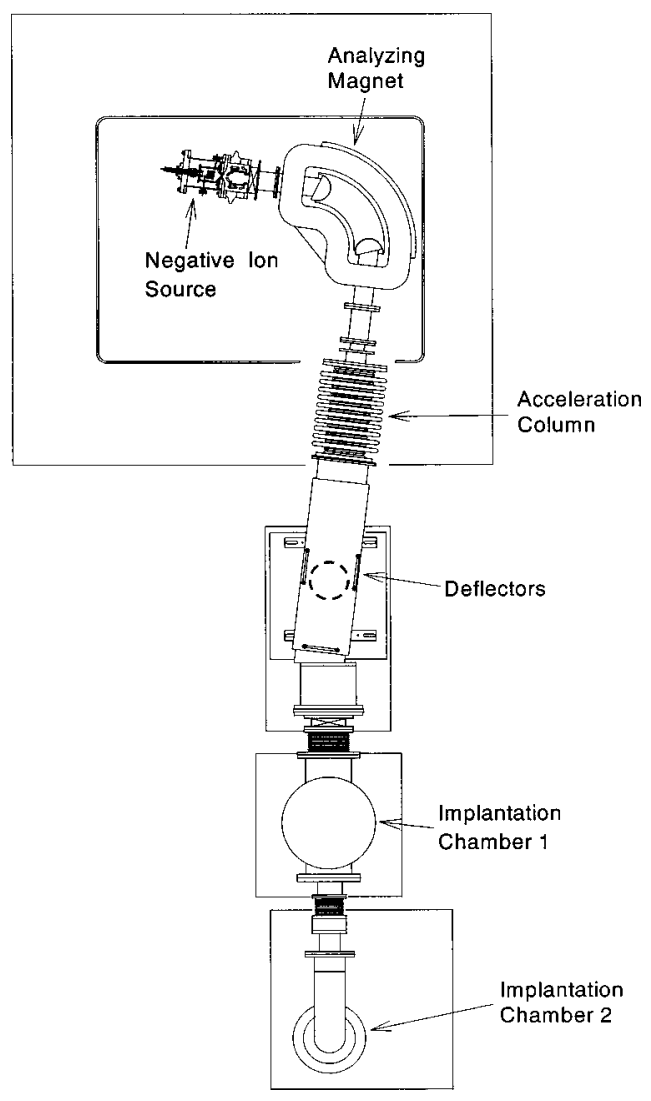

FIG. 1. Schematic configuration of a negative-ion implanter which consists of a plasma-sputter-type negative ion source, a mass separator, an acceleration column, a lens and deflection system, an implantation chamber 1 for flat substrates, a deflector, and an implantation chamber 2 for powder materials

\section{B. Features of negative-ion implantation into powder \\ 1. Nonscattering implantation}

In the negative-ion implantation with any ion of $\mathrm{C}^{-}$, $\mathrm{BO}^{-}$, and $\mathrm{Cu}^{-}$, no scattering was observed for all kinds of powder samples in the size range of $5-1000 \mu \mathrm{m}$ at the vibrated state or at the stationary state. Nonscattering means that charging voltage did not reach the predicted value of several hundreds of volts for scattering. For glass plate, the surface charging voltage was found to be negative, several volts, due to formation of electric double layers. ${ }^{3,4}$ Therefore, the charging voltage of the glass powder is considered to be equal to that of glass plate.

\section{Evaluation of uniformity}

The spherical $605 \mu \mathrm{m}$, glass beads were implanted with $\mathrm{Cu}$ negative ions of $40 \mathrm{keV}$ at an average surface dose of $1 \times 10^{16}$ ions $/ \mathrm{cm}^{2}$ during the agitation. Implantation uniformity was evaluated by the atomic ratio of $\mathrm{Cu} / \mathrm{Na}$ obtained from $x$-ray photoelectron spectroscopy spectra. The average ratio and standard deviation were 0.24 and 0.026 , respectively for ten samples. From this result, good uniformity of implantation was obtained at the vibrating conditions of 120 $\mathrm{Hz}$ and $0.5 \mathrm{~mm}$.

\section{Depth profile}

Depth profiles of $\mathrm{Cu}$ atoms for spherical $605 \mu \mathrm{m}$ glass beads and plane glass implanted with conditions: $70 \mathrm{keV}$,

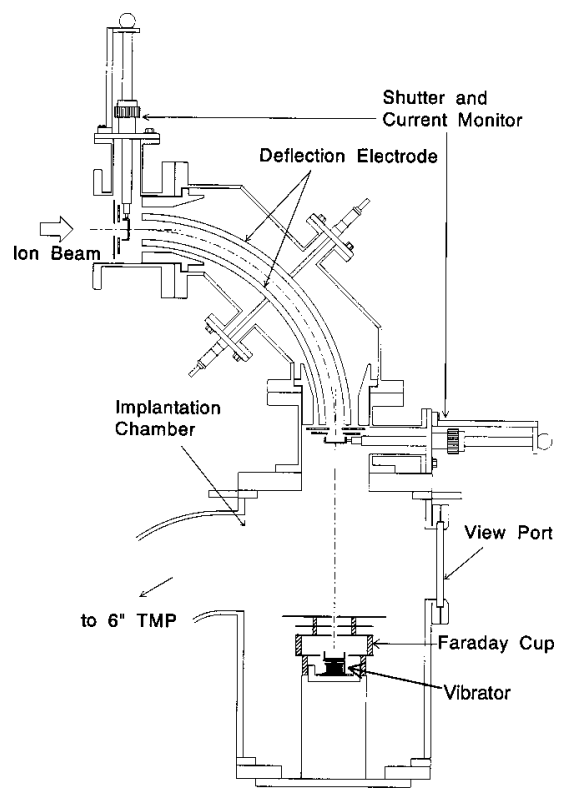

FIG. 2. Enlarged schematic diagram around the implantation chamber 2 for powder.

$1.1 \times 10^{16}$ ions $/ \mathrm{cm}^{2}$ of $\mathrm{Cu}^{-}$were investigated by secondary ion mass spectroscopy. The peak depths were $40 \mathrm{~nm}$ for the bead and $60 \mathrm{~nm}$ for the plane glass. For the implantation into spherical beads, the incidence angle of ions depends on the incident point over the spherical surface, and is changed by the bead rotation due to agitation. Therefore, the depth profile can be calculated by a convolution of penetration profiles depending on the incident angle of a spherical surface and a simple profile obtained from the TRIM code for a flat surface at normal incidence. ${ }^{11}$ Projected range of ion to spherical surface was about $60 \%$ shallower than that in the flat plate, which was in good agreement with the experimental results.

\section{APPLICATION TO FORMATION OF NANOSIZED PARTICLES IN BEAD SURFACE}

\section{A. Experiment}

$\mathrm{Cu}$ negative ions were implanted into spherical sodalime glass beads with an average diameter of $605 \mu \mathrm{m}$ at an ion energy of $50 \mathrm{keV}$ with an average surface dose of 1.0 $\times 10^{17}$ ions $/ \mathrm{cm}^{2}$ during the agitation. The average ion current density was $2 \mu \mathrm{A} / \mathrm{cm}^{2}$. They were also implanted into plane soda-lime glass plate at $30 \mathrm{keV}$ with a dose in a range of $3.0 \times 10^{16}-1.0 \times 10^{17} \mathrm{ions} / \mathrm{cm}^{2}$. Only the glass-plate samples were annealed at 300 and $400{ }^{\circ} \mathrm{C}$ for $1 \mathrm{~h}$ in an atmosphere of argon gas.

For evaluation of nanosized particle in glass, we measured linear optical properties of light transmittance and reflectance in a photon energy range of $1.5-4.5 \mathrm{eV}$ for both $\mathrm{Cu}$-implanted bead and plate samples by using a spectrometer (Shimazu, MPS2000). As for nonlinear optical property, only $\mathrm{Cu}$-implanted glass plates were measured for its nonlinear reflectivity by using a Nd:YAG pulse laser. The laser has a wavelength of $532 \mathrm{~nm}$ with a pulse width of $7 \mathrm{~ns}$ for degenerated four-wave mixing method to obtain the thirdorder nonlinear susceptibility. 


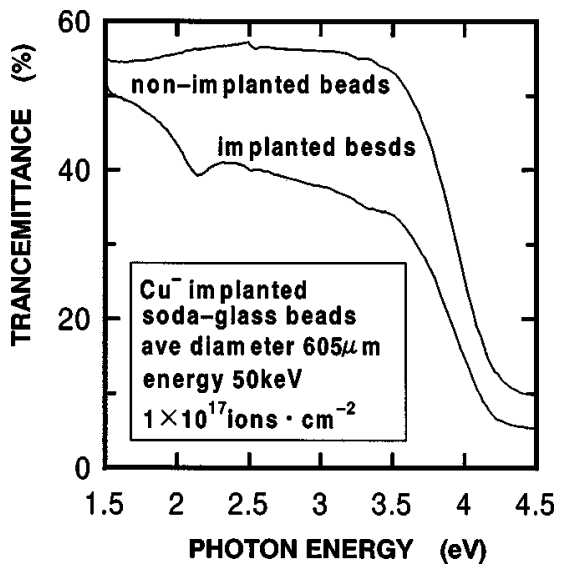

FIG. 3. Transmittance of visible light for $50 \mathrm{keV} \mathrm{Cu}$-implanted and unimplanted soda-lime glass beads as a function of the photon energy.

\section{B. Results and discussion}

\section{Linear optical properties}

Figure 3 shows transmittance of visible light for $50 \mathrm{keV}$ Cu-implanted soda-lime glass beads and unimplanted beads as a function of photon energy. Although the unimplanted beads have no absorption at photon energies below $3.5 \mathrm{eV}$, the curve for $\mathrm{Cu}$-implanted beads has a relatively large optical absorption at around $2.2 \mathrm{eV}$.

Figure 4 shows transmittance of light for $30 \mathrm{keV} \mathrm{Cu}-$ implanted soda-lime glass plate with the parameter of heat treatment: nonannealed, 300 and $400{ }^{\circ} \mathrm{C}$ annealed in $\mathrm{Ar}$ gas for $1 \mathrm{~h}$. The clear absorption peak at around $2.2 \mathrm{eV}$ was found in as-implanted (nonannealed) and $300^{\circ} \mathrm{C}$ annealed samples, but the peak disappeared after annealing at $400^{\circ} \mathrm{C}$.

The absorption peaks for beads and plate are due to a resonance at $2.2 \mathrm{eV}$ of surface plasmon of copper nanosize particle. As for $400^{\circ} \mathrm{C}$ annealed sample, the copper particles were considered to be thermally diffused into the glass plate.

\section{Nonlinear optical properties}

Figure 5 shows a nonlinear reflectivity measured by the degenerated four-wave mixing method with $532 \mathrm{~nm}$ of Nd:YAG laser. From this result, we obtained $1.3 \times 10^{-7}$ esu

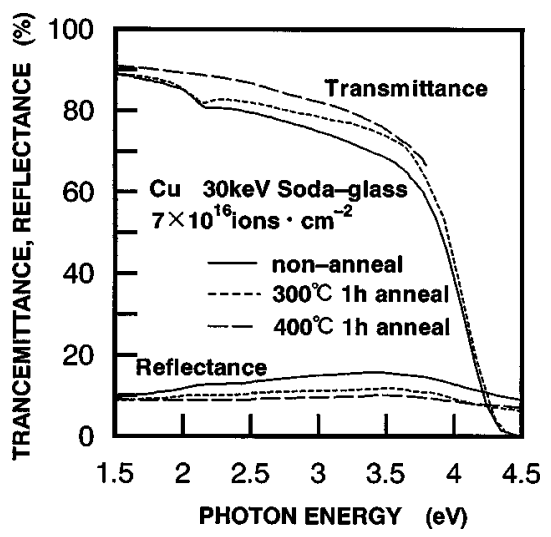

FIG. 4. Transmittance of visible light for $30 \mathrm{keV} \mathrm{Cu}$-implanted soda-lime glass plate as a function of the photon energy with the parameter of heat treatment: nonannealed, 300 and $400{ }^{\circ} \mathrm{C}$ annealed in $\mathrm{Ar}$ gas for $1 \mathrm{~h}$.

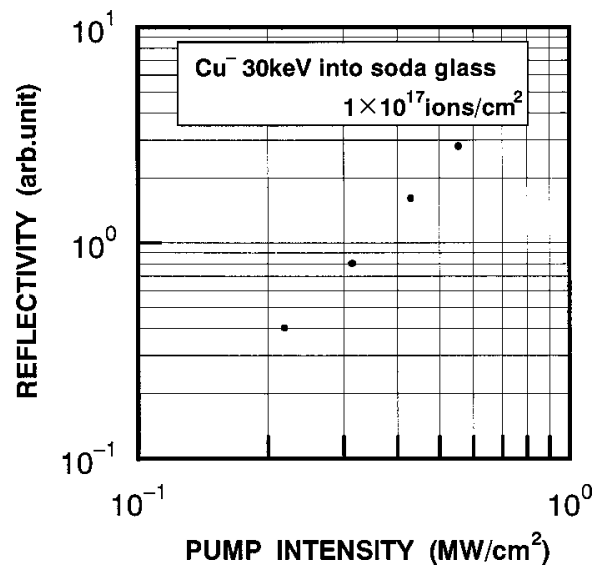

FIG. 5. Relative nonlinear reflectivity for $30 \mathrm{keV} \mathrm{Cu}$-implanted soda-lime glass plate in the degenerated four-wave mixing method with Nd:YAG laser at a wavelength of $532 \mathrm{~nm}$ as a function of the pump intensity.

of nonlinear third-order susceptibility, which is much larger than the value of $\mathrm{CS}_{2}\left(10^{-12} \mathrm{esu}\right)$. This means that the nanosize copper particles were formed at the surface of the glass plate by ion implantation. As for glass beads, we could not measure the nonlinear reflectivity for the implanted glass beads due to strong scattered light at the spherical surface of beads.

\section{ACKNOWLEDGMENTS}

The authors are grateful to Dr. N. Kishimoto and Dr. Y. Takeda at National Research Institute of Metals for the measurement of nonlinear optical properties.

${ }^{1}$ H. Tsuji, Y. Toyota, J. Ishikawa, S. Sakai, Y. Okayama, S. Nagumo, Y. Gotoh, and K. Matsuda, Proceedings of the Tenth International Conference on Ion Implantation Technology-94, Catania, 1994 (Elsevier, New York, 1995), p. 612.

${ }^{2}$ J. Ishikawa, H. Tsuji, Y. Toyota, Y. Gotoh, K. Matsuda, M. Tanjyo, and S. Sakai, Nucl. Instrum. Methods Phys. Res. B 96, 7 (1995).

${ }^{3}$ H. Tsuji, J. Ishikawa, S. Ikeda, and Y. Gotoh, Nucl. Instrum. Methods Phys. Res. B 127/128, 278 (1997).

${ }^{4}$ H. Tsuji, Y. Gotoh, and J. Ishikawa, Nucl. Instrum. Methods Phys. Res. B 141, 645 (1998).

${ }^{5}$ J. H. Freeman and W. Temple, Radiat. Eff. 28, 85 (1976).

${ }^{6}$ S. Durbach, J. Mellor, N. J. Coville, and T. E. Derry, Nucl. Instrum. Methods Phys. Res. B 80/81, 294 (1993).

${ }^{7}$ W. Ensinger and H. R. Muller, Rev. Sci. Instrum. 65, 2963 (1994).

${ }^{8}$ H. R. Muller, W. Ensinger, G. Frech, and G. K. Wolf, Nucl. Instrum. Methods Phys. Res. B 89, 357 (1994).

${ }^{9}$ K. Kajiyama, Y. Suzuki, T. Kokubo, M. Kawashita, and F. Miyagi, Proceedings of the 11th International Conference on Ion Implantation Technology-96, Austin, 1996 (IEEE, Piscataway, 1997), p. 816.

${ }^{10}$ H. Tsuji, J. Ishikawa, H. Itoh, Y. Toyota, and Y. Gotoh, Appl. Surf. Sci. 100/101, 342 (1996).

${ }^{11}$ J. Ishikawa, H. Tsuji, and Y. Gotoh, in Ref. 9, p. 249.

${ }^{12}$ J. Ishikawa, H. Tsuji, M. Mimura, S. Ikemura, and Y. Gotoh, Surf. Coat. Technol. 103/104, 173 (1998)

${ }^{13}$ H. Tsuji, M. Mimura, S. Kido, Y. Gotoh, and J. Ishikawa, Proceedings of the 12th International Conference on Ion Implantation Technology-98, Kyoto, 1998 (IEEE, Piscataway, NJ, to be published).

${ }^{14} \mathrm{H}$. Tsuji and J. Ishikawa, Rev. Sci. Instrum. 63, 2488 (1992).

${ }^{15} \mathrm{H}$. Tsuji, J. Ishikawa, Y. Gotoh, and Y. Okada, Proceedings of the Sixth International Conference on the Production and Neutralization of Negative Ions and Beams, Brookhaven, NY, 1992 [ AIP Conf. Proc. 287, 530 (1994)]. 